\title{
EVASÃO DO CURSO DE PÓS-GRADUAÇÃO EM GESTÃO DE NEGÓCIOS DE UNIVERSIDADE CORPORATIVA: PERCEPÇÕES DO ESTUDANTE/EMPREGADO
}

\author{
EVASION FROM GRADUATE SCHOOL COURSE IN BUSINESS \\ MANAGEMENT OF A CORPORATE UNIVERSITY: \\ STUDENT/EMPLOYEE PERCEPTIONS
}

\section{EVASIÓN DEL CURSO DE POSTGRADO EN GESTIÓN DE NEGOCIOS DE UNA UNIVERSIDAD CORPORATIVA: PERCEPCIONES DE ESTUDIANTES/EMPLEADOS}

\section{Marcelo Almeida de Camargo Pereira ${ }^{1}$ \\ https://orcid.org/0000-0001-5731-341X \\ Luciane de Fátima Giroto Rosa ${ }^{2}$ \\ https://orcid.org/0000-0001-7787-2294 \\ Vera Lucia Felicetti ${ }^{3}$ \\ http://orcid.org/0000-0001-6156-7121}

\footnotetext{
${ }^{1}$ Universidade La Salle, Canoas, Rio Grande do Sul - Brasil. E-mail: marceloacpereira@gmail.com.

${ }^{2}$ Universidade Estadual Paulista, Bauru, São Paulo - Brasil. E-mail: lucianegiroto@ hotmail.com.

${ }^{3}$ Universidade La Salle, Canoas, Rio Grande do Sul - Brasil. E-mail: verafelicetti@ig.com.br.
}

\section{Resumo}

A pós-graduação em Gestão de Negócios é uma realidade e inovação na educação corporativa da instituição federal pesquisada, que, por motivos de segredo industrial não será revelada. $\mathrm{O}$ curso apresenta características inerentes à educação a distância (EaD), como distância no espaço e tempo e a autonomia do aluno. Com relação aos alunos dessa modalidade de ensino, torna-se importante identificar os motivos que levaram muitos deles a evadirem-se do curso. Para tanto, foi aplicado um instrumento de pesquisa cujo objetivo geral foi identificar quais razões levaram o estudante, que é empregado da empresa, a se evadir desse curso. $\mathrm{O}$ instrumento, de caráter quantiqualitativo, continha questões fechadas com respostas a partir da escala Likert, para análise estatística descritiva inferencial, e uma questão aberta, em que foi utilizada a técnica de análise textual discursiva. Evidenciou-se que os motivos que levaram ao elevado número ( $41 \%$ ) de evadidos no curso estão relacionados com: conciliação do tempo para as atividades de trabalho e a necessidade da presença nas atividades síncronas (aulas por videoconferência e provas); necessidade de maior articulação da universidade corporativa da 
empresa com os gestores dos empregados, no sentido de facilitar a participação destes nas atividades presenciais; sensibilização quanto aos aspectos trabalhistas, como férias e especificidades da realidade da empresa, como contingências e greves, entre outros fatores.

Palavras-chave: Pós-graduação. Estudante Trabalhador. Mídias Digitais. Evasão. Ensino a Distância.

\begin{abstract}
The graduate school course in Business Management is a reality and innovation in the corporate education university of the federal public company researched. The course presents characteristics pursuant to Distance Education, such as distance in space and time and student autonomy. Regarding the student of this form of teaching, it is important to identify the reasons that led many of them to evade the course. Given the above, a research instrument was applied, whose general objective was to identify the reasons why the student, who is an employee of the company, evaded this course. The quantitative-qualitative instrument contained close questions with answers based on the Likert scale, for descriptive statistical inferential analysis, and an open question, where the discursive text analysis technique was used. It was evidenced that the reasons that resulted into the high number (41\%) of evaded students in the course are related to: the conciliation of the time for the work activities and the necessity of the presence in the synchronous activities (classes via videoconference and tests); the need for a greater articulation of the corporate university of the company with the managers of the employees, in order to facilitate their participation in face-to-face activities; awareness regarding labor aspects, such as holidays and specificities of the company's reality, such as contingencies and strikes, among other factors.
\end{abstract}

Keywords: Graduate School. Working Student. Digital Medias. Evasion. Distance Study.

\title{
Resumen
}

El curso de postgrado en Gestión de Negocios es una realidad e innovación en la universidad corporativa de una empresa pública donde la pesquisa ha sido desarrollada. El curso presenta características inherentes a la educación a distancia, como la distancia en espacio y tempo y la autonomía del estudiante. En cuanto a los estudiantes de esa forma de enseñanza, es importante conocer las razones las cuales le han hecho abandonar el curso. Con eso, un instrumento de investigación ha sido aplicado, cuyo objetivo general era identificar las razones por las cuales los estudiantes, empleados de la empresa, abandonaron el curso. El instrumento quantitativo-qualitativo contenía preguntas cerradas con respuestas basadas en la escala Likert, para análisis estadístico descriptivo inferencial, así como una pregunta abierta, donde la técnica de análisis textual discursivo fue empleada. Se mostró que las razones que resultaron en un gran número de evadidos (41\%) están relacionadas con: conciliación del tiempo para las actividades de trabajo y la necesidad de estar presente en las actividades sincrónicas (clases y testes por medio de videoconferencias); necesidad de mayor articulación entre la universidad corporativa y los gerentes de los empleados para facilitar su participación en las actividades presenciales; sensibilización de la empresa cuanto a los aspectos laborares, como las vacaciones y especificidades de la realidad de la empresa, como contingencias y huelgas, entre otros factores.

Palabras clave: Postgrado. Estudiante empleado. Medios digitales. Evasión. Enseñanza a distancia. 


\section{Introdução}

Atentas ao mercado de frequentes mudanças e características concorrenciais, diversas organizações, públicas e privadas, procuram estruturar sua área de Recursos Humanos, dando maior atenção à formação e ao desenvolvimento de seus colaboradores. Dessa forma, no Brasil, assim como em outros países, as instituições têm investido em Universidades Corporativas (UCs) para a elaboração de cursos com recursos internos, objetivando maior efetividade na formação de seus líderes e demais profissionais, em um contexto "de associação entre educação, modernidade e competitividade" (EBOLI, 2005, p. 118).

Instituições como Banco do Brasil (UniBB ${ }^{1}$ ), Petrobras, Bradesco (Fundação Bradesco - Escola Virtual ${ }^{2}$ ), Correios (UniCorreios ${ }^{3}$ ) e até o Sistema Único de Saúde - SUS (UnaSus ${ }^{4}$ ) são apenas alguns exemplos de grandes instituições que atuam no Brasil e possuem universidades corporativas estruturadas. A intenção de manter no quadro próprio uma estrutura de UC está diretamente relacionada com o retorno, não apenas para os funcionários, mas para a instituição como um todo em relação à gestão do conhecimento e ao desenvolvimento de habilidades específicas para o desenvolvimento de seus negócios.

Para essas empresas de grande porte, a educação a distância (EaD), com a disponibilização de materiais on-line e possibilidade de acesso em qualquer tempo ou lugar, desponta como uma tendência para a disseminação rápida de temas e conteúdos.

Para esta pesquisa foi selecionada uma instituição pública federal de grande porte, presente em todos os estados brasileiros e no Distrito Federal, e que também tem em seus quadros uma universidade corporativa estruturada. Pelo sigilo na divulgação de maiores detalhes do negócio, não divulgaremos o nome da instituição em respeito à ideia de segredo industrial. Aderente ao contexto e à necessidade de atualização profissional de seus empregados, a Universidade Corporativa da instituição pesquisada começou a oferecer, em 2017, o Curso de Pós-Graduação em Gestão de Negócios. Essa especialização, planejada para ter duração de três semestres, contou com intensa participação de diversos atores da empresa: professores, estudantes, suporte e monitores, distribuídos em diversos estados no Brasil.

\footnotetext{
${ }^{1}$ Disponível em: https://www.unibb.com.br/login?to=\%2f. Acesso em: 27 ago. 2018.

${ }^{2}$ Disponível em: https://www.ev.org.br/. Acesso em: 27 ago. 2018.

${ }^{3}$ Disponível em: http:// http://unicorreiosvirtual.correios.com.br/. Acesso em: 27 ago. 2018.

${ }^{4}$ Disponível em: https://www.unasus.gov.br. Acesso em: 27 ago. 2018.
} 
A primeira turma, que teve a oferta de disciplinas curriculares finalizada em julho de 2018, continuou em andamento até setembro do mesmo ano, quando encerrou-se o prazo para entrega do trabalho de conclusão de curso em forma de artigo científico. O curso oferecido tratou-se de um projeto piloto na empresa e inovador no campo do ensino mediado por tecnologia, com material de estudo e realização de atividades assíncronas (e-books, vídeos, exercícios, fóruns etc.) disponibilizados no Ambiente Virtual de Aprendizagem (AVA) da instituição e com aulas a distância, com encontros síncronos realizados por webconferência, em que alunos e professores interagiam em tempo real com as ferramentas disponibilizadas pela tecnologia, uma das características da EaD (MAIA; MATTAR, 2007).

Essa metodologia de ensino, além da mediação tecnológica, apresenta diferentes características, se comparadas com a educação presencial, como a relativização do tempo e espaço, o deslocamento do foco do ensino para a aprendizagem do aluno, assim como a autonomia deste em gerir o tempo e ritmo de seus estudos.

A disciplina necessária para administrar o tempo, considerando a condição paralela de estudante e trabalhador, tem se apresentado como um fator crítico na $\mathrm{EaD}$, visto que muitos alunos ainda estão acostumados às características da educação presencial, na qual o tempo dedicado às aulas e atividades está mais definido. Embora a segunda modalidade também exija a autonomia do aluno, conciliar o trabalho com o estudo dos materiais no AVA e a realização dos exercícios, sem a presença física de professor e colegas, mostra-se como um dos desafios do aluno trabalhador do ensino mediado pela tecnologia.

Isso pode fazer que muitos alunos dessa modalidade se evadam do curso, conforme demonstram os dados do Censo da Educação a Distância, conduzido pela Associação Brasileira de Educação a Distância (ABED), os quais indicam que as "taxas de evasão [...] recaem principalmente na faixa entre 11\% e 25\%" (ABED, 2017, p. 151). Segundo o mesmo censo, essa faixa percentual de evasão refere-se a instituições que oferecem cursos regulamentados, graduações e pós-graduações inteiramente a distância. Por outro lado, nas que oferecem cursos corporativos livres, a faixa de evasão é ainda maior, no patamar de $26 \%$ a $32 \%$, enquanto os cursos semipresenciais têm proporção de evasão menor, localizada na faixa entre $6 \%$ e $10 \%$.

Ainda segundo a ABED (2017), as instituições públicas são as que menos conhecem os motivos que levam os alunos a evadirem-se de um curso a distância. Na Figura 1, extraída do mesmo estudo, verificam-se os graus de concordância quanto aos motivos de evasão em cursos regulamentados. 
Figura 1 - Graus de concordância quanto aos motivos de evasão em cursos regulamentados.

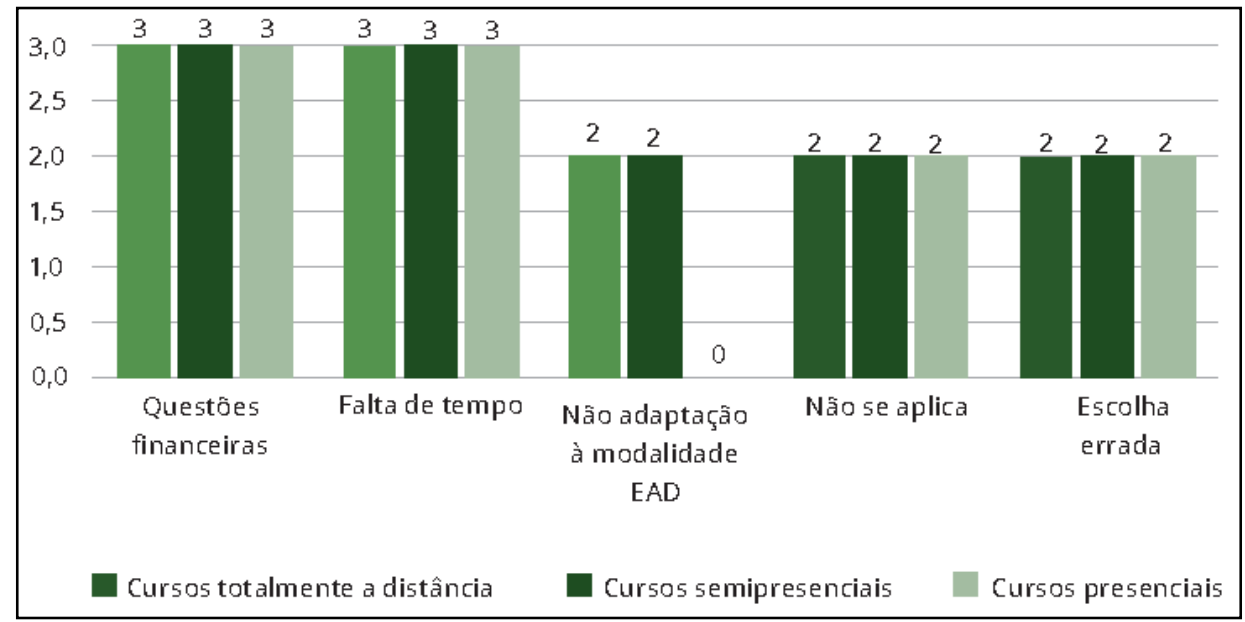

Fonte: ABED, 2017.

Entre os principais motivos apresentados na Figura 1 estão as questões financeiras, a falta de tempo, a não adaptação à modalidade EaD e a escolha inadequada do curso. Essas informações justificam a investigação do que pode estar por trás do elevado número de evasões verificado na pós-graduação oferecida pela instituição pesquisada, ou seja, em que, de um total de 152 alunos matriculados inicialmente, $41 \%$ se evadiram. Assim, com os resultados do presente estudo, pretende-se oferecer à organização subsídios para que a mesma possa se planejar e ajustar-se à oferta futura de novos cursos, administrando adequadamente os recursos existentes e contribuindo para a efetividade do aprendizado.

Com isso, o objetivo do presente estudo foi identificar os fatores que levaram os estudantes da instituição a se evadirem do curso de pós-graduação em Gestão de Negócios oferecido gratuitamente.

O artigo foi, então, organizado em quatro partes: 1 - Introdução e Justificativa, em que se contextualizam o tema e a escolha da instituição pesquisada; 2 - Metodologia, na qual se detalham os materiais e métodos para o presente estudo; 3 - Análise dos dados, em que os resultados obtidos e sua relação com o problema de pesquisa são apresentados e discutidos; e 4 - Considerações finais, item no qual são apresentadas as reflexões finais e sugestões de pesquisas futuras sobre a temática. 


\section{Metodologia}

A abordagem da pesquisa tem caráter quantitativo e qualitativo. O estudo, de natureza descritiva conforme os ensinamentos de Gil (2002, p. 42), "tem como objetivo primordial a descrição das características de determinada população ou fenômeno ou, então, o estabelecimento de relações entre variáveis". Assim, para evidenciar os principais motivos que levaram à alta evasão do curso pesquisado, utilizaram-se instrumentos de coleta de dados que proporcionassem análises quantitativas e qualitativas.

No contexto do curso da pós-graduação em Gestão de Negócios, como foi dito anteriormente, observou-se um total de 64 alunos evadidos, número composto por trancamentos, desistências e desligamentos, representando um percentual de $41 \%$ dos 152 alunos matriculados inicialmente. Tal percentual mostra-se acima dos apresentados no censo da ABED (2017). Dessa forma, foram enviados, por e-mail, 64 questionários aos alunos evadidos, com prazo de retorno de nove dias corridos, sendo que se obteve uma taxa de retorno de $56,25 \%$, ou seja, 36 participantes responderam ao instrumento enviado.

$\mathrm{Na}$ parte quantitativa, os sujeitos da pesquisa (estudantes evadidos) avaliaram afirmações de múltipla escolha, onde marcaram uma das cinco alternativas referentes a questões pertinentes ao seu percurso acadêmico na pós-graduação, e uma questão aberta dissertativa. As questões de múltipla escolha fizeram uso da estrutura visualizada na escala Likert de cinco pontos, as quais foram: Discordo Totalmente; Discordo; Indiferente; Concordo; e Concordo Plenamente (VIEIRA; DALMORO, 2008), aplicadas em um instrumento de pesquisa apresentado no Quadro 1. 
Quadro 1 - Questões e opções de resposta ao instrumento de pesquisa com evadidos no curso de pós-graduação em GNC

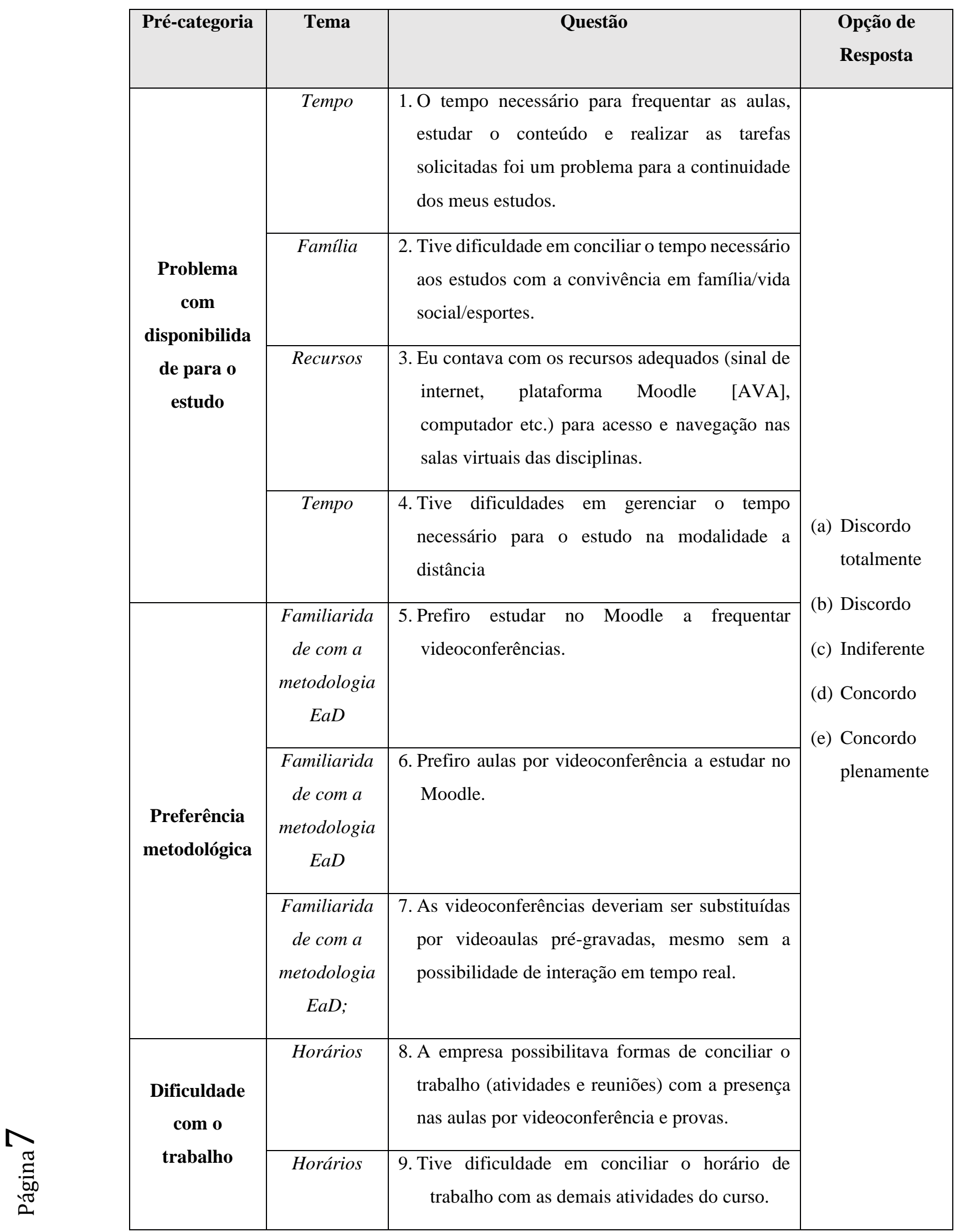




\begin{tabular}{|c|c|c|c|}
\hline & $\begin{array}{l}\text { Crescimento } \\
\text { profissional }\end{array}$ & $\begin{array}{l}\text { 10. A pós-graduação me possibilitaria novas } \\
\text { oportunidades dentro da empresa. }\end{array}$ & \\
\hline & Investimento & $\begin{array}{l}\text { 11. A gratuidade foi um fator decisivo para minha } \\
\text { inscrição nesse curso de pós-graduação. }\end{array}$ & \\
\hline & $\begin{array}{l}\text { Atuação } \\
\text { Universidad } \\
e\end{array}$ & $\begin{array}{l}\text { 12. Um maior envolvimento dos gestores pela } \\
\text { instituição pública federal pesquisada reduziria } \\
\text { o índice de faltas nas aulas por } \\
\text { videoconferência. }\end{array}$ & \\
\hline \multirow{5}{*}{$\begin{array}{l}\text { Satisfação } \\
\text { com o curso }\end{array}$} & Distribuição & $\begin{array}{l}\text { 13. O equilíbrio entre as atividades no Moodle e as } \\
\text { videoconferências foi adequado. }\end{array}$ & \\
\hline & $\begin{array}{l}\text { Qualidade } \\
\qquad \text { das } \\
\text { disciplinas e } \\
\text { conteúdos }\end{array}$ & $\begin{array}{l}\text { 14. A qualidade das disciplinas e do conteúdo do } \\
\text { curso estava de acordo com as minhas } \\
\text { expectativas. }\end{array}$ & \\
\hline & $\begin{array}{c}\text { Aplicabilida } \\
\text { de para a } \\
\text { instituição } \\
\text { pública } \\
\text { federal } \\
\text { pesquisada }\end{array}$ & $\begin{array}{l}\text { 15. Os conteúdos do curso podem ser aplicados na } \\
\text { instituição pública federal pesquisada. }\end{array}$ & \\
\hline & $\begin{array}{c}\text { Qualidade } \\
\text { dos docentes }\end{array}$ & $\begin{array}{l}\text { 16. O desempenho dos professores da pós- } \\
\text { graduação, em termos de conhecimento, } \\
\text { experiência, assim como suas práticas } \\
\text { didáticas, foi adequado. }\end{array}$ & \\
\hline & Currículo & $\begin{array}{l}\text { 17. A grade curricular deveria ser revista, } \\
\text { substituindo unidades curriculares pouco } \\
\text { relevantes para a empresa. }\end{array}$ & \\
\hline Evasão & Motivos & $\begin{array}{l}\text { 18. Quais motivos levaram você a desistir da pós- } \\
\text { graduação em Gestão de Negócios da } \\
\text { instituição pública federal pesquisada? }\end{array}$ & Resposta aberta. \\
\hline
\end{tabular}

Fonte: Elaborado pelos autores.

De acordo com o Quadro 1, é possível perceber que foram identificadas categorias $a$ priori, como: problema com disponibilidade para o estudo, que continha questões relacionadas 
com família, tempo e recursos; preferência metodológica, que agregava questões sobre a familiaridade com a metodologia $\mathrm{EaD}$; dificuldade com o trabalho, com questões relacionadas com horários, crescimento profissional e atuação da Universidade Corporativa; insatisfação com o curso, em que estão agrupadas questões referentes às disciplinas da pós-graduação em questão, aplicabilidade de conteúdos, avaliação docente, currículo, assim como uma categoria específica chamada "vasão, que continha a questão aberta.

A partir do relatório gerado pelo sistema onde a pesquisa foi gerada, as questões quantitativas foram organizadas no Excel e importadas pelo EPI-INFO versão 7.1. Nesse arquivo, as respostas da escala Likert tiveram valores atribuídos, a saber: discordo totalmente foi substituído por 0 ; discordo, por 1; indiferente, por 2; concordo, por 3; e concordo plenamente, por 4. Verificou-se que as questões 3, 8, 10, 11, 12 e 16 do Quadro 1 são positivas, às quais foram atribuídos valores assim representados: quanto maior o grau de concordância, menor a pontuação obtida na questão, ao passo que, nas questões negativas, quanto maior o grau de concordância, maior a pontuação.

A relevância atribuída a cada pré-categoria foi calculada pela soma das respostas às questões com impacto negativo e o inverso da pontuação atribuída das respostas às questões com impacto positivo. Por exemplo, para a pré-categoria "Problema com disponibilidade para o estudo", as questões 1, 2 e 4 foram somadas ao inverso da questão 3. Nesse caso, os valores atribuídos à questão 3 passaram a representar $0=$ concordo totalmente e $4=$ discordo totalmente. A soma das respostas obtidas foi então dividida pelo maior somatório possível em cada pré-categoria e expressa em percentual. Dessa forma, o valor percentual atribuído a cada pré-categoria representa a relevância atribuída pelo aluno na pré-categoria.

Para a parte qualitativa foi empregada uma questão dissertativa, na qual as respostas dos sujeitos foram analisadas via técnica de análise textual discursiva, proposta por Moraes e Galiazzi (2007). Essa técnica pressupõe um processo de categorizações que possibilita uma compreensão emergente sobre um tema.

As respostas à questão aberta passaram por um processo de desconstrução, categorização e unitarização (agrupamento em um único texto), formando novas categorias de sentido e dialogando, quando possível, com os dados das questões fechadas.

Desse texto, que se tornou o corpus de análise, foram realizadas diversas leituras, a fim de se obterem categorias emergentes. Por meio dessas leituras, as palavras que agruparam sentidos foram grifadas com diferentes cores, as quais auxiliaram nas categorias emergentes, 
cujo processo culminou em um novo texto, também chamado de metatexto, o qual respondeu à questão de pesquisa aqui proposta e será apresentado no item "A resposta emergente". Dados da análise estatística inferencial no item "Dados quantitativos" auxiliaram a corroborar essa análise.

Os itens "Dados quantitativos" e "Dados qualitativos" apresentam as análises dos dados quantitativos e qualitativos, respectivamente, enquanto o item "A resposta emergente" se dedica à apresentação da resposta emergente à questão de pesquisa.

\section{Apresentação e análise dos dados}

Apresentam-se, neste tópico, a análise dos dados quantitativos cujos procedimentos foram descritos na Metodologia, assim como os qualitativos. Ambas as análises serão entrelaçadas, auxiliando a melhor delinear a resposta emergente.

\subsection{Dados quantitativos}

Os dados, cujo tratamento foi descrito na metodologia desta pesquisa, propiciaram a elaboração de duas tabelas e um gráfico, os quais serão apresentados a seguir. A Tabela 1 mostra a distribuição das relevâncias percentuais (em intervalos e geral) atribuídas pelos alunos em cada pré-categoria. 
Evasão do curso de pós-graduação em Gestão de Negócios de Universidade Corporativa: percepções do estudante/empregado

Tabela 1 - Relevâncias percentuais atribuídas pelos alunos em cada pré-categoria.

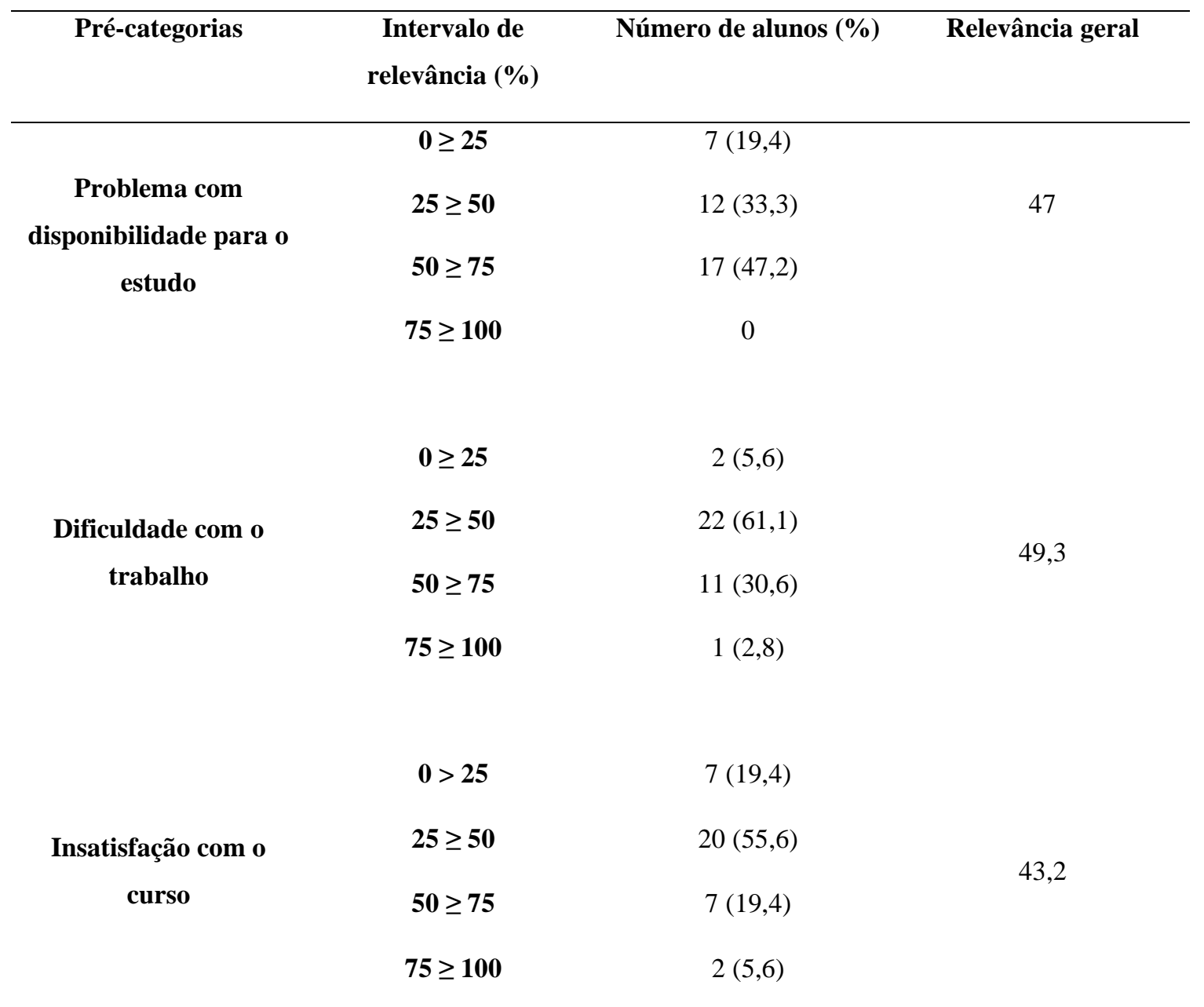

Fonte: Elaborado pelos autores.

Verifica-se na Tabela 1 que ter disponibilidade para o estudo foi um problema para $47 \%$ dos 36 evadidos. Aspectos atinentes à pré-categoria "Dificuldade com Trabalho" que representaram os empecilhos à permanência no curso tiveram 49,3\% das respostas dos 36; e "Insatisfação com o Curso", com 43,2\% dos respondentes, concordando que as características/formato do curso foram obstáculos à permanência dos alunos. Observa-se ainda. na Tabela 1, na pré-categoria "problema com a disponibilidade para o estudo", que o maior percentual encontrado está no intervalo $50 \geq 75$, ou seja, 47,2\% dos 36 evadidos respondentes tiveram dificuldade igual ou maior que $50 \%$ com a disponibilidade para o estudo. Já na précategoria "Dificuldade com o trabalho", o maior percentual $(61,1 \%)$ de respostas ficou no intervalo $25 \geq 50$.

Para a pré-categoria "Preferência Metodológica" elaborou-se a Figura 2 a seguir. 
Figura 2 - Preferência Metodológica

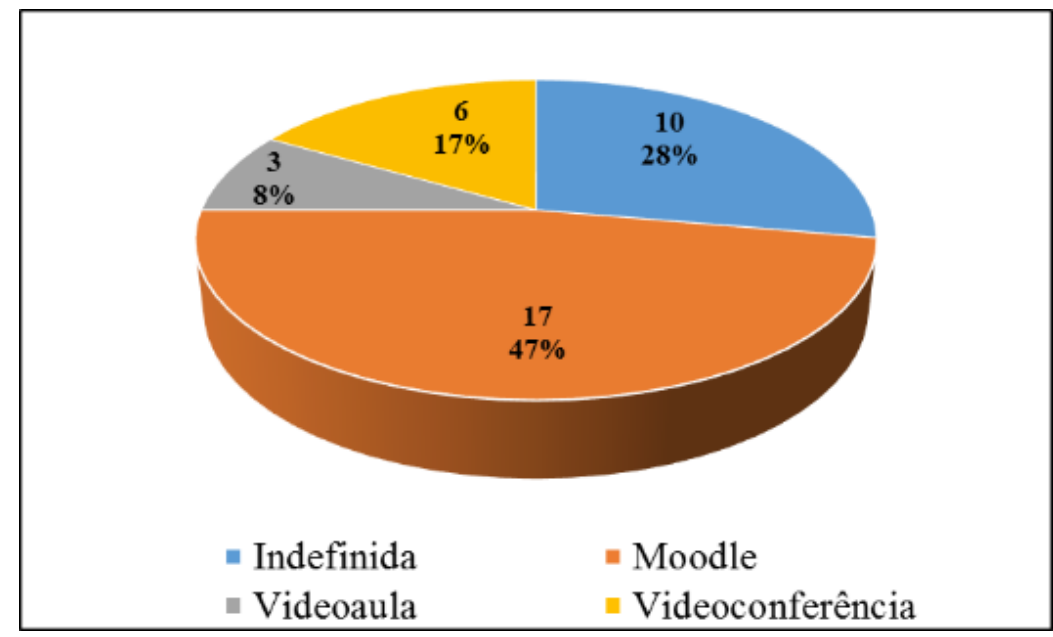

Fonte: Elaborado pelos autores.

Observa-se na Figura 2 que 47\% dos sujeitos pesquisados (17 pessoas) preferem o AVA-Moodle para as aulas, $17 \%$ (seis pessoas) preferem as aulas por videoconferência e $28 \%$ (10 respondentes) são indiferentes ao método com o qual as aulas ocorram. Apenas três pessoas foram favoráveis ao uso de videoaulas pré-gravadas.

Tabela 2 - Médias de problemas com disponibilidade para o estudo para cada nível de preferência metodológica.

\begin{tabular}{lccc}
\hline & $\begin{array}{c}\text { Número de } \\
\text { alunos }\end{array}$ & Média & $\begin{array}{c}\text { Desvio } \\
\text { padrão }\end{array}$ \\
\hline Indefinida* & 10 & 33,13 & 19,99 \\
Moodle** & 17 & 48,90 & 13,84 \\
Videoaula & 3 & 68,75 & 6,25 \\
Videoconferência & 6 & 54,17 & 19,63 \\
\hline
\end{tabular}

Fonte: Elaborado pelos autores.

${ }^{*} p<0,05$ na comparação com todas as outras preferências.

** $p=0,06$ na comparação com a videoaula. 
A Tabela 2 mostra a média dos problemas enfrentados com a disponibilidade para o estudo para cada preferência metodológica. Os 10 alunos que apresentaram preferência metodológica indefinida, ou seja, atribuíram concordância semelhante às diferentes possibilidades de estudo, quer sejam Moodle, videoaula ou aula por videoconferência, apresentaram a menor média de problemas. Os que preferiram o Moodle demonstraram ter $48,9 \%$ de problemas com a disponibilidade para o estudo. O grupo com maior percentual de problemas foi o dos que preferiram a videoaula, sendo significativamente maior que os indefinidos e indicativo de significância na comparação com os que preferiram o Moodle. Os resultados demonstram que a videoaula é utilizada como um recurso mais frequente entre os que enfrentam esses problemas.

Na Tabela 3 é possível observar as questões que tiveram médias acima de 2, lembrando que a maior média é 4 e que tais questões foram consideradas negativas, sendo a elas os valores assim atribuídos: quanto maior a concordância, maior a pontuação.

Tabela 3 - Questões de impacto negativo com maiores médias.

\begin{tabular}{lc}
\hline \multicolumn{1}{c}{ Questão } & $\begin{array}{c}\text { Média } \\
\text { da } \\
\text { questão }\end{array}$ \\
\hline $\begin{array}{lc}\text { 9. Tive dificuldade em conciliar o horário de trabalho com as } \\
\text { demais atividades do curso. }\end{array}$ & 3,03 \\
$\begin{array}{lc}\text { 1. O tempo necessário para frequentar as aulas, estudar o } \\
\text { conteúdo e realizar as tarefas solicitadas foi um problema para }\end{array}$ & 2,67 \\
a continuidade dos meus estudos. & \\
$\begin{array}{ll}\text { 17. A grade curricular deveria ser revista, substituindo } \\
\text { unidades curriculares pouco relevantes para a empresa. }\end{array}$ \\
$\begin{array}{ll}\text { 4. Tive dificuldades em gerenciar o tempo necessário para o } \\
\text { estudo na modalidade a distância. }\end{array}$ & 2,06 \\
\hline
\end{tabular}

Fonte: Elaborado pelos autores. 
Conforme a Tabela 3, a questão 9 apresentou a maior média $(3,03)$, seguida pelas questões 1 , com 2,67; 17, com 2,25; e 4, com 2,06. Esses dados indicam que a dificuldade em conciliar o horário de trabalho com as demais atividades do curso e o tempo necessário para frequentar as aulas, estudar o conteúdo e realizar as tarefas solicitadas, bem como gerenciar o tempo ao estudo, foi, sim, um obstáculo à permanência no curso e interveniente na evasão. $\mathrm{O}$ descontentamento com a grade curricular também se apresenta com uma pontuação relevante entre os alunos evadidos.

\subsection{Dados qualitativos}

Dos 36 participantes da pesquisa, apenas um não respondeu à questão aberta: “Quais motivos levaram você a desistir da pós-graduação em Gestão de Negócios da instituição pública federal pesquisada?". A partir do relatório fornecido pelo sistema de pesquisa regional, gerouse uma planilha em Excel, na qual o texto de cada participante foi dividido em uma célula. Com a leitura das respostas, foi possível distribuí-las nas categorias apresentadas no Quadro 1: Problema com disponibilidade para o estudo, em que respostas que tivessem teor de problemas pessoais que interferiram no caminho da formação foram alocadas; Dificuldade com o trabalho, com as respostas relacionadas com temas que englobassem as interações entre empregado e empresa, coordenação do curso e questões trabalhistas; e, por fim, a categoria Insatisfação com

$\underline{\text { o curso, }}$, contendo as respostas que contivessem teores pertinentes a aplicação, questões pedagógicas, planejamento das aulas, dinâmica das videoconferências etc.

As falas dos estudantes/empregados aqui inseridas serão doravante citadas como empregado + letra do alfabeto, seguindo a ordem de citação dos excertos, de forma a manter a confidencialidade mencionada no convite de participação.

\subsubsection{Problema com disponibilidade para o estudo}

A primeira categoria apresentou apenas três respostas. Nelas, apareceram problemas de saúde dos empregados (que ensejaram o afastamento da atividade), assim como gravidez de uma participante. 


\title{
3.2.2 Dificuldade com o trabalho
}

Essa categoria foi a mais representativa para análise. Foram, no total, 26 respostas que continham questões aderentes à categoria, que, por sua vez, acabou sendo subdividida nas seguintes subcategorias: função, transferência, férias e motivação. Inicia-se a análise por meio do excerto a seguir:

\begin{abstract}
Da mesma forma que a empresa me propiciou uma oportunidade, infelizmente ela também me tirou, pois o curso tem dinâmica própria, independente e indiferente à rotina da empresa. Durante a pós, meu trabalho passou por modificações profundas em razão da reestruturação, minhas obrigações aumentaram e a empresa me obrigava a frequentar o curso e a continuar comparecendo aos compromissos, trabalhando mais de 10 horas por dia para dar conta, já que o trabalho de alguns passou a ser feito por um. Enfim: ou eu tocava bem o meu trabalho ou fazia a pós-graduação. Pensando no meu futuro, optei por fazer bem o meu trabalho atual (e não perder a função) em vez de investir no futuro, correndo sério risco de ter outro em meu lugar, muito embora eu saiba que isso não seria diretamente relacionado aos estudos. Em suma, a empresa deu, a empresa tirou. Sem mágoas nem rancores, pois sempre há uma opção diferente e eu fiz a escolha de forma consciente. Espero que um dia a empresa decida realmente o que quer; se irá valorizar o aprendizado, tem que saber que vai abrir mão de um tempo do empregado... (Resposta do empregado A, grifo nosso).
\end{abstract}

$\mathrm{Na}$ fala do funcionário, constatam-se críticas em relação aos efeitos que as mudanças provenientes da reestruturação causaram no percurso da pós-graduação. Outras também vêm no mesmo sentido, destacando não a reestruturação em si, mas a perda da função ou acúmulo de atividades. Houve também um relato de empregado cuja desmotivação ensejou em início de depressão.

Nesse caminho, mais um relato importante apresentado por outra empregada:

Na verdade, eu não desisti da pós. Sempre tive total interesse em continuar na pós e estava me dedicando a isso. Acontece que atualmente ocupo uma função [...] a qual não me dava possibilidade de assistir às videoconferências. Fui removida da pós, exclusivamente por questões profissionais e todas devidamente comprovadas. As minhas faltas eram todas por compromissos com a empresa, os quais eu não poderia deixar de estar presente, a exemplo de reuniões com a presidência da empresa, vicepresidência, departamento ao qual sou subordinada, viagens a serviço, convocação para reunião em BSB e tudo isso com as comprovações das convocações. Nenhuma falta foi por outro motivo. Tudo isso foi exposto à universidade para que a possibilidade de continuar fosse revista, tendo em vista as faltas comprovadas por necessidade da empresa. Sinto muito por ter deixado a pós e mais uma vez venho pedir encarecidamente que situações como essas sejam reavaliadas, considerando que não se trata de algo que eu, como aluna e empregada, possa intervir ou mudar. (Resposta da empregada B, grifo nosso). 
Conforme o relato da funcionária, que optou por se identificar na resposta (sendo seu nome retirado em razão do sigilo prometido), verifica-se o dilema que se apresentou aos alunos durante o curso: comparecer à videoconferência ou às reuniões e/ou demais atividades de trabalho?

A subcategoria "transferência" agregou apenas duas respostas de empregados que tiveram problemas em razão de transferência de área e de estado, que interferiram na presença nas videoconferências e atividades da pós. Já a subcategoria "férias" apresentou quatro respostas com menção à suspensão das férias imposta pela empresa, com desdobramentos na conciliação dessas com o calendário acadêmico.

\subsubsection{Incentivo}

A última e mais relevante subcategoria é a "Incentivo". Inicia-se como exemplo a partir da seguinte resposta:

Conciliação serviço x aula. O horário não foi compatível, além de ficar mal visto por estar frequentando a aula no horário de serviço. (Resposta do empregado $\mathrm{C}$, grifo nosso).

A fala desse funcionário apresenta um dos quesitos que orientaram a subcategoria, que é agrupar respostas que tenham teor crítico quanto à postura da empresa no sentido de facilitar a participação dos empregados nas atividades síncronas da pós-graduação, ou seja, nas aulas por videoconferência e/ou provas.

Foram 14 respostas que continham esse teor, sendo que elas apresentavam: situações relacionadas com a estruturação da empresa, mas que denotavam a falta de incentivo para a continuidade dos estudos; temas associados à constante adequação do calendário acadêmico, o que resultava em faltas dos participantes; questões relacionadas com o conflito atuação profissional versus presença nas videoconferências; e questões físicas, nas quais um empregado que trabalhava das 0h:00min às 8h:00min alega ter tido dificuldades de concentração.

Apesar de serem apontamentos que poderiam ser contabilizados às subcategorias reestruturação e função, verificou-se, nas críticas dos respondentes, que a empresa poderia ter patrocinado e promovido maior incentivo aos empregados no sentido de favorecer o 
comparecimento às aulas e atividades. Essas críticas não se colocam aos gestores imediatos, a exemplo da fala adiante:

A SE (Superintendência Estadual) passava por muita dificuldade operacional à época, fator que pesava na ausência da posição de trabalho para assistir às videoconferências e elaborar as atividades extraclasse, em que pese não ter havido de meus gestores qualquer pressão para desistir. Foi uma decisão pessoal originária de conflito interno decorrente de compromissos com a organização. (Resposta do empregado D, grifo nosso).

Um apontamento interessante, que apareceu em outra resposta, e que pode suscitar novas provocações e reflexões:

Dificuldade em conciliar as videoconferências e provas presenciais com o horário de trabalho. As aulas e provas deveriam ocorrer fora do horário de trabalho. (Resposta do empregado E, grifo nosso).

A palavra conciliar apareceu seis vezes nas formas desinencial e derivada (sob a forma de conciliação). Nessa ótica, a responsabilidade pela conciliação das atividades da pós durante o horário de trabalho (videoconferência e provas) recaía sobre os empregados. Cabe a reflexão que emerge dessas falas: em uma pós-graduação oferecida pela empresa, o empregado tem de escolher entre executar as atividades inerentes ao trabalho ou se dedicar ao aprimoramento acadêmico/intelectual?

\subsubsection{Insatisfação com o curso}

A última categoria agrega respostas relacionadas com o objetivo do curso, questões burocráticas da coordenação, críticas sobre o modelo pedagógico dos professores, ao calendário acadêmico e às realidades da empresa, ao não reconhecimento do curso pelo MEC e quanto ao trabalho de conclusão do curso.

Foram nove respostas enquadradas nessa categoria. A continuidade da análise se dá por meio da fala a seguir: 


\begin{abstract}
Não percebi um padrão pedagógico entre aulas presenciais, atividades on-line, leituras obrigatórias ou sugeridas e provas. A cada semana era uma surpresa, portanto creio que, inicialmente, deveria haver um trabalho pedagógico que integrasse os professores, as aulas e demais atividades, estabelecendo, assim, um padrão e cronograma de atividades que pudessem ser realizados sem correria, com aprendizado e aplicação prática. Até onde fui com as aulas, não consegui perceber aplicação prática na gestão e na rotina da empresa. [...] Sempre adorei estudar, mas preciso sentir que estou evoluindo e me senti muito conturbada enquanto permaneci no curso. (Resposta da empregada F, grifo nosso).
\end{abstract}

Outra resposta também vai ao encontro da fala da funcionária anterior, que chamou as videoconferências de "monótonas e repetitivas". Em relação à grade curricular especificamente, apareceu somente uma fala, afirmando que o modelo inicial da pós parecia mais atraente quando havia um eixo básico e eixos específicos para determinadas áreas de negócio da empresa.

Por fim, houve apenas uma resposta que abordou diretamente a modalidade de educação a distância, na qual o empregado assumiu que não conseguiu se adaptar a essa forma de aprendizagem.

\title{
3.2.5 A resposta emergente
}

A técnica de análise textual discursiva adotada na análise dos dados qualitativos obtidos no instrumento aplicado tem por finalidade a elaboração de um metatexto, o qual mantém profunda relação com as categorias apresentadas.

Nesse caminho, busca-se responder ao objetivo desta pesquisa apresentado na parte introdutória, que é "identificar os fatores que levaram o estudante da instituição pública federal pesquisada a evadir-se do curso de pós-graduação em Gestão de Negócios”. Isso será feito por meio de um texto autoral em que não há juízo de valor, mas que contém sugestões e críticas provenientes das falas dos sujeitos respondentes.

Dado o exposto, os motivos que levaram à evasão dos alunos na instituição pública federal pesquisada foram: o tímido apoio da empresa, no sentido de assegurar ao empregado, via mediação da universidade da instituição pública federal pesquisada, a sensibilização dos gestores dos empregados para a importância e oportunidade que a pós-graduação em Gestão de Negócios da instituição pública federal pesquisada proporciona. Essa sensibilização favoreceria a presencialidade do empregado, que não pode se dividir entre exercer suas atribuições e comparecer aos eventos síncronos da pós; a necessidade de maior articulação do calendário acadêmico com as realidades e especificidades da empresa, de forma que os funcionários 
possam conciliar as atividades acadêmicas e profissionais; pouca flexibilidade quanto à suspensão das férias dos alunos da pós, com suas inevitáveis implicações sobre a sua motivação ; as aulas por videoconferência, as quais deveriam ter seu papel rediscutido para eventual redução ou substituição por aulas pré-gravadas; e a didática das aulas em geral, que pede melhorias quanto aos aspectos pedagógicos, promovendo maior significado ao estudante/empregado, isto é, que contribua para o desenvolvimento de competências para sua atuação profissional.

\section{Considerações finais}

A educação corporativa firmou-se no Brasil a partir dos anos 2000 como uma prática nas instituições com o fim de auxiliar a disseminação dos saberes para a continuidade do negócio e a gestão do conhecimento organizacional.

Conhecer o contexto do estudante/empregado é conhecer a realidade do sujeito que faz os negócios acontecerem, o qual também é destinatário dos esforços da área de educação corporativa para a concretização dos objetivos estratégicos da organização.

Dentro das facilidades que a educação a distância propicia, na qual o estudante dita o ritmo de seus estudos, verificam-se também alguns pontos de reflexão, especialmente quanto à evasão de estudantes. Nesse sentido, o referido trabalho serviu para que os pesquisadores pudessem conhecer com maior profundidade os motivos que levaram à evasão do curso de pósgraduação em Gestão de Negócios da instituição pesquisada, de forma a apontar sugestões de ajustes à empresa para as futuras ofertas do curso a partir dos dados levantados e analisados.

Por meio de duas "frentes" metodológicas, uma quantitativa e outra qualitativa, a partir da aplicação de um questionário aos alunos evadidos, verificou-se que: um apoio mais enfático da empresa para o autodesenvolvimento, a discussão sobre qual mediação pedagógica o curso de pós-graduação deveria adotar, assim como as experiências que a coordenação do curso adquiriu para a consecução e materialização do curso, poderiam ter minimizado a evasão dos estudantes da pós em Gestão de Negócios, em que o tempo se tornou um obstáculo à concretização do percurso formativo.

Sugere-se, por fim, que os estudantes/empregados aprovados, agora egressos da pósgraduação também sejam pesquisados, de forma a se obter amplo conhecimento a respeito do curso, agregando as compreensões desses egressos, assim como a dos evadidos. 


\section{Referências}

ABED. Associação Brasileira de Educação a Distância. Censo EAD.BR: relatório analítico da aprendizagem a distância no Brasil 2016. Censo EAD.BR [livro eletrônico]/[organização] ABED - Associação Brasileira de Educação a Distância; Curitiba: InterSaberes. Disponível em: http://abed.org.br/censoead2016/Censo_EAD_2016_portugues.pdf. Acesso em: 15 ago. 2018.

BÓS, A. J. G. EpiInfo sem mistérios: um manual prático. Porto Alegre: EDIPUCRS.

Brasil. Lei no 6.538 de 22 de junho de 1978. Disponível em:

http://www.planalto.gov.br/ccivil_03/LEIS/L6538.htm. Acesso em: 1 out. 2018.

EBOLI, M. O papel das lideranças no êxito de um sistema de educação corporativa. In:

Revista de Administração de Empresas. v. 45, n. 4, p. 118-122. 2005. Disponível em: http://bibliotecadigital.fgv.br/ojs/index.php/rae/article/viewFile/37316/36079. Acesso em: 30 set. 2018.

GIL, A. C. Como Elaborar Projetos de Pesquisa. 4. ed. São Paulo: Atlas, 2002.

MAIA, C.; MATTAR, J. ABC da EaD - A educação a distância hoje. 1. ed. São Paulo: Pearson Prentice Hall, 2007.

MORAES, R.; GALIAZZI, M. do C. Análise Textual Discursiva. Ijuí: UNIJUÍ, 2007.

VIEIRA, K. M.; DALMORO, M. Dilemas na Construção de Escalas tipo Likert: o número de itens e a disposição influenciam nos resultados? In: XXXII Encontro da ANPAD, 2008, Rio de Janeiro. Anais [...]. Rio de Janeiro: Anpad, 2008. Disponível em:

http://www.anpad.org.br/admin/pdf/EPQ-A1615.pdf. Acesso em: 30 set. 2018.

Recebido em: 25/12/2018

Aprovado em: 03/08/2020

Publicado em: 15/03/2021 